\title{
Editorial
}

\section{Education Reforms and Social Change}

As a topic in the sociology of education, educational change has been high on the agenda of scholars, practitioners and policy-makers alike. In fact, over the previous several decades, both social and political changes, as well as technological innovation, have been a catalyst for changes in education. Yet, educational change is not only a reflection of larger social and political transformations as well as initiatives aimed at reshaping educational practice but an amalgam of factors (both internal and external) that have an impact on schooling as well as on education in general.

Interestingly, scholarship on educational change has been galvanised not only by these transformations but also by an increasing significance of education for both individual and social well-being. This period coincided with some of the major shifts of emphasis in education policy-making on a global level and scholarly endeavour that had a transformative influence on theorising in social sciences and the humanities. In particular, the centrality of education in post-1989 social and political changes has contributed considerably to several system-based reforms throughout Europe. One of the paths undertaken has been that of Slovenia. After a decade of conceptual discussions and a panoply of 'scaling up' projects and other initiatives, a comprehensive educational reform was undertaken in 1996.

This focus issue of the CEPS journal (entitled Education Reforms and Social Change) aims to bring together a set of contributions discussing the impact and the legacy of the introduction of nine-year comprehensive education alongside changes at the legislative, organisational, and curriculum levels from pre-primary to vocational and general upper-secondary education, including higher education, of a newly established independent state. Twenty-five years later, this educational reform continues to stimulate discussions about public as well as private education (both in Slovenia and in other countries in the region). This focus issue, therefore, includes articles that discuss a particular aspect of this reform as well as papers that reflect the broader social and political circumstances that have influenced change in education and continue to do so. While focusing on Slovenia, it simultaneously includes reflections on the educational reforms and other initiatives in the selected European countries both from the south and the north.

The article authored by Hannele Niemi, entitled Education Reforms for Equity and Quality: An Analysis from an Educational Ecosystem Perspective with 
Reference to Finnish Educational Transformations, starts with the question of why educational reforms do not lead to better learning. Although access to education has increased remarkably, the quality can be very low. The reality is that by 2030800 million educated young people will not have basic skills in reading and math. The author seeks answers to the question of why it is so with the concept of the educational ecosystem, asking how different subsystems, such as curriculum system, evaluation systems, teacher education policy, and labour market, should be interconnected, and systemic changes supported by all these subsystems. The basic conditions are that different actors and stakeholders work in collaboration. There are active interactions within and between different subsystems for supporting both equity and quality in education. Educational reforms are complex processes and need diverse partners and governance among whom trust is required. The article also provides a brief case description in Finnish contexts of how educational reforms have been implemented in the frame of the ecosystem concept. In the end, the article summarises how educational ecosystems could help to overcome the global learning crises.

Georgeta Ion, Cecilia Inés Suárez, and Anna Diaz Vicario, in their article Evidence-Informed Educational Practice in Catalan Education: From Public Agenda to Teachers' Practice, reflect on Catalonia's long tradition of school innovation movements, which have increased in recent years as public administration and private entities initiated substantial school reforms oriented toward the use of evidence in teaching practice. As the Catalan educational system is highly autonomous, not all schools embraced the evidence-informed practise (EIP) movement; this has created differences between schools that choose to implement a change or an innovation based on scientifically demonstrated evidence and those that do not. That is why our authors attempt to understand the current state of the inclusion of the EIP in Catalonia and the teachers' perceptions regarding its adoption as part of their daily practice. To address the abovementioned, they have started exploring the legal and structural framework grounding the implementation of EIP in the Catalan system and, through interviews conducted with a sample of primary school leaders and teachers, they have approached the organisational and individual levels to explore the opportunities to implement an authentic EIP approach in the Catalan educational system.

In the next article, The Impact of Specific Social Factors on Changes in Education in Serbia, Ana Pešikan and Ivan Ivić examine political and economic changes that followed the adoption of the Strategy for the Development of Education in Serbia (2012), which largely left aside the basic ideas and intentions of the strategy, creating the systematic threat to education and its role in the 
development of Serbia. In the opinion of the authors, this made an almost experimental situation for analysing the impact of political and social factors on changes in education. In the sphere of politics, new trends have emerged (centralisation of power; marginalisation of democratic institutions; encouraging foreign investment in companies with a low technological level, etc.) that all strongly influenced the changes ('reforms') in education (great centralisation in education, strong influence of politics on education, imposing of some lower-level forms of education, reducing professional autonomy, etc.). The basic mechanism of transferring general policy to education is changing the role of the most important national institutions in defining and implementing education policy. The adoption of new education laws (2017) radically changed their status and competencies, resulting in a reduction of their independence and professionalism and a strengthening of the role of the Ministry, through which the influence of the ruling politic is transferred. Also, the role of the Chamber of Commerce in education has been strengthened. Such changes, according to the authors, have endangered the autonomy of educational institutions and teachers, as well as the quality of education. Consequently, these changes have a clear impact on the country's development and its international position in the field of education.

Slavko Gaber and Veronika Tašner, in their paper Structural Over-Determination of Education Reforms and Agency, conceptualise the relationship between the individual and the structural in a time of relatively radical changes in society. The dialectics of such relationships are analysed through a combination of auto-ethnographic reflections and archival documents showing the changes in the functioning of a council of experts in a country that experienced and managed three fundamentally peaceful transitions: the transition from a selfgoverning socialist economy to a market economy, from a one-party socialist system to a representative liberal democracy, and from a republic that was part of a federal state to an independent state. The contextualised account and assessment of the shifts that together helped produce the independent state and its formation of the educational system outline the complexity and importance of reflexive governance during times of transition, which in itself foregrounds a number of relevant issues and invites and supports change in the educational system.

The article by Mitja Sardoč, entitled Citizenship, Social Change, and Education, discusses some of the neglected aspects associated with the justification of citizenship education in public schools. The central purpose is to explain the two main impulses associated with the civic aims of public schools and their interrelationship with social changes. The main part contrasts these 
two opposing motivational impulses associated with the reasons for citizenship education. Each of the two impulses is presented and then clarified with an example to shed light on the basic justificatory procedure associated with it. The concluding part of this paper outlines the most distinctive challenges: the alternative conception of justifying citizenship education and its interplay with social change.

The article Consequentialist Reasons for Some Education Reforms by Zdenko Kodelja identifies two contrasting reasons for educational reforms: consequentialist and non-consequentialist. In particular, it examines proposed education reforms in some of the EU countries whose strategic aims have been equated with creativity and innovation and whose main form of justification has been a consequentialist one. As the author emphasises, it seems that the introduction of such education reforms can be understood not as a decision founded on causal explanation but rather on the basis of a special type of teleological explanation, which has the logical form of 'practical syllogism'.

Marjan Šimenc's contribution, entitled Education Reform and the Normalisation of Private Education in Slovenia, to this focus number of the CEPS Journal examines 'the long-term effects of the regulation of private education adopted in the education reform in 1996 and the sustainability of the guiding principles that served as the starting point for this regulation'. In particular, it reviews both the main goals of the education reform as explicated in the 1995 White Paper, the guiding principles of the introduction of private education in Slovenia, as well as the regulations introduced based on these tenets. It also takes a closer look at the establishment of private education in Slovenia based on the adopted regulation and its relationship with public education. As the author accentuates, ' $[\mathrm{t}]$ he thesis proposed by the article is that it is the normalisation of private education in Slovenia that should be considered the main achievement of the education reform'

Živa Kos's contribution, entitled Shifting Regulative Ideas of Education Policy and Practice: The Case of Quality Assurance in Education in Slovenia, attempts to show how societies and schools have for some time functioned through the regulation of three dispositives: the legal, the disciplinary, and the security dispositives. While the crises of the 1970s shifted the combination of dispositives in education in the West towards security ones, this shift in the rationality of educational policy and practice in Slovenia did not take place until the 1990s, after the broader political transition to democracy and a market economy. The paper aims to illustrate these shifts through the structuring of quality assurance mechanisms in education in Slovenia over the last two decades. 
Ljubica Marjanovič Umek in her paper A New Image of Preschool Institutions in Slovenia: Conceptual, Systemic and Curricular Backgrounds presents an analysis of preschool education in Slovenia. Her analysis is based on theoretical starting points, international comparative analysis of quality indicators of preschool education and curriculum documents, and the results of Slovenian and foreign empirical research on children's early development and learning. The analysis was conducted from the point of view of conceptual, systemic, and curricular solutions. The author particularly emphasises the need to update the preschool curriculum and professional dilemmas related to the efficiency and fairness of preschool. In conclusion, the author highlights selected opportunities for improvement in Slovenian preschool education.

The article by Mojca Kovač Šebart, Damjan Štefanc, and Tadej Vidmar Compulsory Education Reform between the Profession and Policy in the Light of Justice and Equal Opportunities provides a detailed and critical insight into selected elements of the reform of primary education in independent Slovenia. The reform of primary education in Slovenia was based on the 1995 concept White Paper, which formed the basis for the adoption of the relevant legislation. Since there were more solutions than could be problematised in one paper, the authors focus only on a few selected solutions. They have been usefully divided into three groups: System, Programme, and Process groups. The text also points out that more attention should be paid to reducing inequalities related to social and cultural realities and different regions in Slovenia. For the programme level, the authors point out the need to reach a consensus on what quality general education means. For the process level, they note that there is not enough professional support or systematic evaluation studies. The authors believe that the quality of schools cannot be measured solely on the basis of the results of international research.

We round up this focus number with Pavel Zgaga's article, From a National University to a National Higher Education System. In line with the idea of 'focus', the author addressed the conceptualisations and gradual transformation of higher education from the 1980 os to the early 1990 os in Slovenia. His reflection is thus dedicated to the period of profound social and political changes leading to the proclamation of the independent Republic of Slovenia (1991). The broad public debate on the future of education was an important part of the awakening of civil society in the 1980 os in general. In the specific field of higher education, intensive discussions led to the demand for a new and comprehensive development strategy. Given the profound transformation of higher education during this period, this subject has been unjustifiably poorly researched. The presented article, therefore, attempts to contribute to partially filling the gap and at the 
same time to stimulate further research of the topic. The present analysis, based on the study of archive material, concludes that the most important innovation of this period can be defined as a gradual conceptual and then normative shift from a national university to a national higher education system.

The paper by Hajnalka Fényes included in the Varia section of the $2^{\text {nd }}$ issue of the 2021 volume of the CEPS Journal, entitled Paid Work Alongside Higher Education Studies as an Investment in Human Capital, examines the contribution of working (while studying) to individuals' human capital. In particular, the author examines whether Bourdieuan capital conversion is characteristic of students. The results of the survey that was carried out in the Central European region point toward a mutual advantage understanding of higher education students' paid work (while studying) for all the actors involved.

The book review included in this focus number of the CEPS Journal takes a closer look at the volume Performative Approaches to Education Reforms edited by Dorthe Staunæs, Katja Brøgger and John Benedicto Krejsler (Routledge, 2019).

The overall aim of this focus issue of the CEPS Journal has been to discuss the various issues that any education reform brings along. Alongside vertical and thematically oriented criteria, a particular focus has been made on the issues addressed by the authors of these contributions that reflect the broader social and political circumstances that impact educational change. Given the tumultuous changes brought by the Covid-19 pandemic as well as a panoply of issues as diverse as populism, fake news, hate speech, the shrinking civic space, and similar, there are many topics to be explored further, not only in how education can respond to them but also how education shapes the future of our societies.

Mitja SARdoč, Veronika Tašner and Slavko Gaber 